\title{
Support for a Unique Theory of Definiteness
}

\author{
Barbara Abbott \\ Michigan State University
}

\section{Introduction}

The familiarity theory of definite descriptions and the classical theory (often referred to as the 'uniqueness' theory) are well known. On the familiarity view of definiteness, what differentiates the definite article from the indefinite article is whether the NP denotes an existing discourse referent or a novel one. On the classical view the primary difference is a uniqueness/exhaustiveness proposition, which is associated with the definite article but not the indefinite. There is in addition the difference of whether the existence proposition, which is associated with both, is grammatically presupposed or not-presupposed for definites, but not necessarily for indefinites. For the familiarity theory see Christophersen 1939, Heim 1982, 1983, Chafe 1996, among many others. For the uniqueness view see Russell 1905, Löbner 1985, Kadmon 1990, Hawkins 1991, among many others.

It has been suggested (e.g. by Birner \& Ward 1994, Poesio \& Vieira 1998) that neither theory can account for all the data, suggesting that both are needed. That would be an unsatisfactory conclusion. For one thing, it implies an ambiguity where none is felt. For another, since the two theories are on different levels (pragmatic and semantic), one would like to unify them, ideally by explaining one kind of generalization based on the other.

In this paper I want to take steps toward resolving this problem. The logical first step is settling on the right theory. At this point I want to acknowledge the fairly decisive evidence already given against the familiarity theory. The bottom line is that there are many examples of definite NPs that denote entities which are not already part of the discourse context and not assumed to be familiar to the addressee. See e.g. Hawkins 1991, Gundel et al. 1993, Birner \& Ward 1994, and Poesio \& Vieira 1998 for examples and additional references. It is of ten thought that these examples can be handled via the accommodation principle of Lewis 1979. Abbott 1999 argues (completely convincingly in my opinion) that as a general strategy this won't do. In the next section of this paper I will give three new arguments which add cement to the shoes of the familiarity theory. Following that we will need to look at a couple of kinds of cases which seem to present problems for the classical view. The penultimate section contains an attempt to explain the appeal of the familiarity theory, and is followed by concluding remarks.

\section{New arguments}

\subsection{Focus Phenomena}

The first new argument is based on the consequences of focusing the definite article. Current approaches agree that focused elements make implicit reference to paradigmatic alternatives (see Rooth 1992, Krifka 1993, Pulman 1997). Focusing the definite article invokes a contrast with its alternative, expressed by the indefinite article. Consider the result, as in (1).

(1) THE person who could have convinced me to join that club just quit himself. 
(1) conveys strongly the speaker's assumption that only one person could have convinced her to join the club. The contrast is one of uniqueness vs. plurality, not familiarity vs. novelty.

Related focus phenomena confirm this pattern. Contrasting the indefinite with the definite article brings out clearly the uniqueness element that distinguishes them.

That wasn't A reason I left Pittsburgh, it was THE reason.

There is nothing to do with familiarity or novelty expressed in (2), but just how many reasons it took to convince the speaker to leave Pittsburgh. Similarly focusing the indefinite article by itself strongly conveys nonuniqueness:

He was A friend; I had others.

Even when there is no explicit contrast with the indefinite article, there must generally be at least a possibility of more than one entity which meets the descriptive content of a definite NP for it to make sense to focus the definite article. If the article is totally predictable it does not convey additional information and so usually cannot be stressed. Hence the oddness of examples like (4).

\#We saw THE Statue of Liberty!

(4) is awkward because it forces the interpreter to construct a context in which there is possibly more than one Statue of Liberty. This implicit contrast with plurality provides the humor in the seasonal cartoon shown in Figure 1.

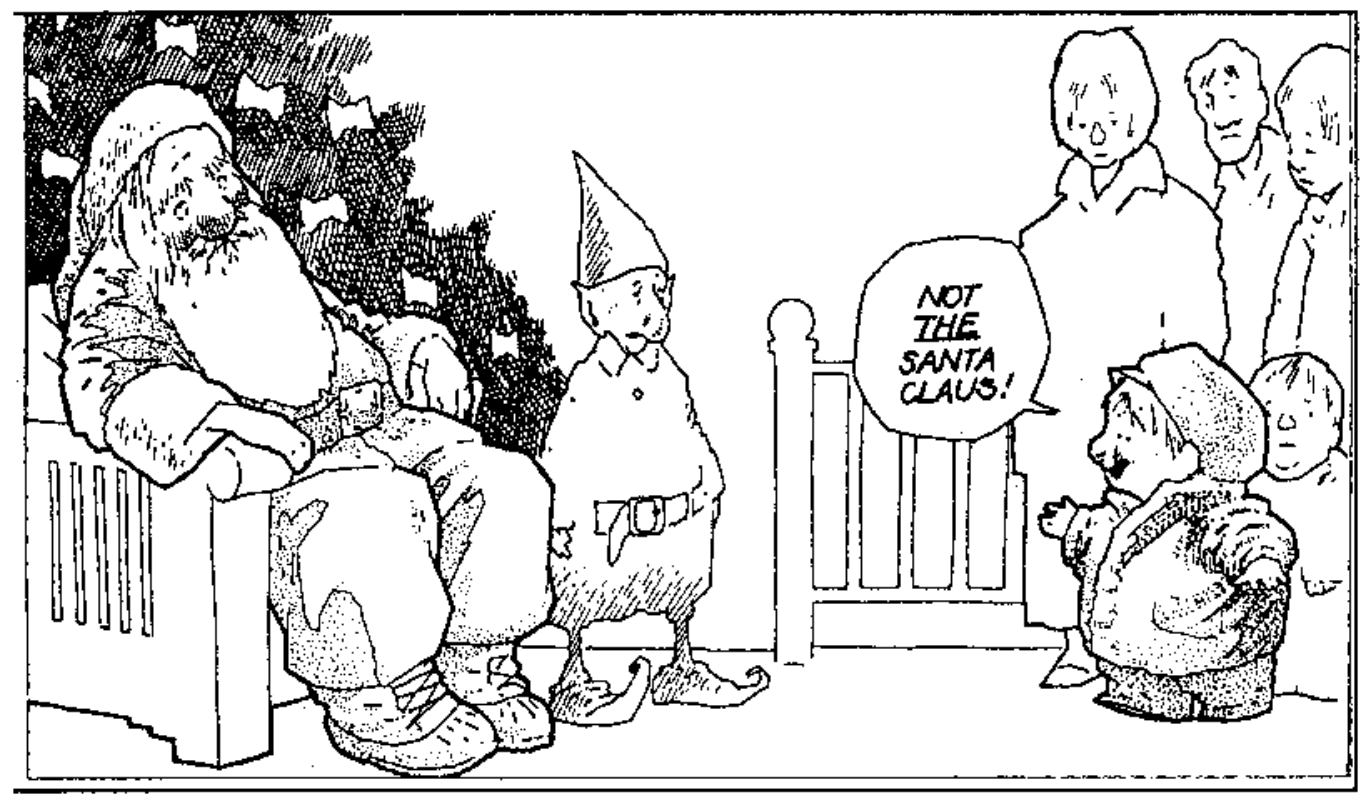

Figure 1. Cartoon by Dick Guindon, Detroit Free Press, 24 December 1997, 3F. Used with permission. 
Richard Epstein has pointed out to me that it is possible to use a stressed definite article in at least some cases where the article is totally predictable, notably in sentences with superlatives such as (5):

That was THE best pizza I've ever had.

However it is also the case that superlatives have an exaggerating use in which uniqueness is not entailed and which do not even behave like definites, as in (6):

(6) There was the best pizza I've ever had as an appetizer at that party.

It seems plausible that the stressed the in sentences like (5) is possible because of the non-literal nature of this construction. (See also example (8) below.)

In this light, consider the following example from Epstein 1996:

In other countries, soccer is the sport. If the national team loses, there could be a coup. [Los Angeles Times 6/5/94, p. C9; italics in the original; = Epstein 1996, ex. 2]

Epstein describes this example as one showing that stressed the signals 'prominence' or 'great importance'. However it seems more accurate as well as less vague to describe (7) as conveying this prominence through hyperbole. Obviously soccer isn't the only sport in any country, but to describe it as such in forceful terms, as is done in (7), is to convey its prominence in a specific way. So on my account the speaker of (7) says literally that soccer is the only sport. This is almost certainly false, invoking standard Gricean mechanisms to arrive at the hyperbolic understanding. In support of this claim notice that one could replace THE sport in (7) with the only sport, achieving the same effect although in a slightly more heavy-handed way. I want to make clear that I am not claiming that the and the only are completely synonymous, but only that they share the uniqueness element of meaning that is at issue here. (I will argue below in section 3.1 that there are semantic differences between the and the only, but the implication of uniqueness is not among them.) (8) below is another naturally occurring example of stressed the where the referent is not actually the unique satisfier of the description; (8) also is another example of the exaggerated superlative. In this example the hyperbole is tacitly acknowledged. ${ }^{1,2}$

'People say it's the night that the movers and shakers are going,' a mischievous-sounding Gehry said when he was asked about his Thursday invitation. 'I was told, of course, that every night is the most important one,' Gehry...added. 'But I was told that this was the most important one.' [The New Yorker 12/22\&29/97, p. 50; italics in original]

None of these examples seem to have anything to do with the familiarity of the referents of the definite descriptions involved, and hence are problematic for the familiarity theory of definiteness.

\subsection{Existentials}

The second argument concerns analyses of the definiteness effect in existential sentences, and actually has several subarguments. We will be shifting gears in this section to focus on the existential proposition associated with definite descriptions, rather than the uniqueness proposition. Here the contrast between the familiarity theory and the classical theory is more subtle-essentially whether the existential 
presupposition is assumed to be known to the addressee, or merely grammatically presupposed. In brief, the line is that recognizing the correctness of the classical view results in a simpler, more correct, and more explanatory analysis.

There are many analyses of the definiteness effect currently on offer, of course, but a converging group assume the familiarity theory of definiteness in one way or another. McNally 1992, 1998 is one especially well worked out example, which I will summarize here very briefly, omitting many important details. Following Lumsden 1988, McNally divides the definiteness effect in existential sentences into two cases. Quantified NPs are excluded from existentials semantically, because they are not predicative. Definite descriptions, proper names, and pronouns are excluded only pragmatically, and it is here that the familiarity theory comes into play. Ignoring some nontrivial details, McNally's view of definites is essentially Heim's. In order to account for their infelicity in existentials McNally suggests the following:

The use of There be is felicitous in a context $\mathrm{C}$ only if the NP $\alpha$ serving as its argument carries the condition that any discourse referents it licenses be novel. [= McNally 1998, ex. 50]

As McNally notes, this condition is similar to those suggested by Lumsden 1988 , Zucchi 1995, and Ward \& Birner 1995; the account in Musan 1996 is also similar to McNally's in this respect.

There are several problems with this stipulation of the infelicity of familiar referents in existentials. For one thing, the fact that it IS an ad hoc stipulation is a problem. I don't want to belabor this methodological point, but technically speaking any such stipulation could be as easily replaced by its negation as not, for all the explanatory value it has.

Secondly, as is well known, there are numerous counterexamples to this stipulation. (10a) is an enumerative existential (these are called 'contextualized existentials' in Abbott 1993), and (10b) is a type of refocusing existential.

a. What can we use to hold the door open? Well, there's the encyclopedia...

b. I think there was one flight where we had one problem. It wasn't ours, but there was that one flight. [Challenger commission transcripts, 4/2/86; = Ward \& Birner 1995, ex. 10]

McNally 1992 recognizes these cases, and suggests the principle in (11) to nullify the Felicity Condition in (9):

(11) If an existential sentence is presupposed to be true in the context in which it is uttered, its (re-)introduction into the context is not accompanied by the instantiation of any discourse referent. [= McNally 1992, ex. 345.]

Her rationale: 'conversation participants should be willing to acknowledge that the individuals needed to support the truth of the utterance have already been instantiated...' (McNally 1992, 164). In other words the felicity condition is lifted when the existential is presupposed to be true. But this amounts to almost exactly the conditions when the felicity condition would be invoked in the first place.

The examples in (10) show that the focus NP in an existential can denote a familiar referent, contrary to felicity conditions like that in (9). What has not been noted before, at least as far as I know, is the converse kind of problem for the 
familiarity approach-definite NPs which denote UNfamiliar referents which are nevertheless NOT suitable in existentials. (12) is one example:

\section{\#There is the first customer to show up waiting to see you.}

The underlined NP in (12) is one of Millikan's necessarily identifying descriptions (Millikan 1984, 181), and it introduces a novel entity into the discourse. The existence of novel definites by itself is of course problematic for the familiarity theory, as noted at the outset. The point here is that novel definites do not conflict with the felicity condition in (9). Thus (12) should be natural, but it is not. This is an additional problem for the familiarity theory.

None of these problems will arise on the classical view, with one proviso. The proviso is that grammatical presuppositions should not be identified with material in the common ground. Of course without this proviso the classical view would in a sense incorporate the familiarity theory, including the problems noted above. That is, if, contrary to what I am supposing, grammatical presuppositions were required to be part of the common ground, then the presupposition of existence of a referent for a definite description would be attributable as prior knowledge to the addressee of an utterance, which is essentially the familiarity theory. In Abbott 1999 independent arguments are given which oppose this identification in general, and not just for the presuppositions associated with definite descriptions.

Given this proviso, we are free of the problems raised above. First of all we do not need the ad hoc stipulation of a requirement that existentials introduce a novel referent into the discourse. All we need to do is recognize that (positive declarative) existential sentences assert (or directly entail, as in McNally's analysis) the existence of a referent for the focus NP. This by itself creates a conversational tension with the existential presupposition of definite NPs on the classical view. It is generally not felicitous to assert something while presupposing it. The result is the requirement of a special context for existentials with definites. Since no stipulated novelty condition is required, there is no need for a countervailing condition to lift this condition. And we predict that novel definites, which do share the grammatical presupposition of existence, should show the same kind of awkwardness as other types of definites. ${ }^{3}$ On this view, then, the conflict is between the assertion of existence concurrent with the grammatical presupposition of existence, rather than between a stipulated requirement that existentials introduce a novel discourse referent and a faulty theory that definite descriptions denote preexisting discourse entities.

\subsection{Written vs. spoken texts}

The third new argument in favor of the classical view of definite descriptions emerged in a preliminary study of naturally occurring data. $\mathrm{We}^{4}$ compared definite descriptions in a spoken text (an excerpt from the radio call-in show Car Talk) with definite descriptions in written texts (front page newspaper stories from three newspapers: the Los Angeles Times, the Washington Post and the St. Louis PostDispatch). The basic finding was that the written texts included a greater number of definite descriptions that introduce new discourse entities than did the spoken texts. Such descriptions are often notable for their length, which makes sense given that a novel definite must uniquely identify a referent from the world at large, whereas one that denotes a discourse entity must only distinguish it from other entities in the discourse. (Compare the very similar phenomenon investigated by Krauss \& Glucksberg 1964, 1977 and Clark \& Wilkes-Gibbs 1986. I am grateful to Doug 
Davidson for reminding me of this research, and supplying references.) Some examples are given in (13)
a. the harassing behavior that has become commonplace in many workplaces [Detroit News, 6/29/98]
b. the few audience segments that can quickly generate widespread support for a new show [Washington Post, 10/21/98]
c. the section of the West Bank city of Hebron that Israel handed over to the Palestinians [Los Angeles Times, 10/21/98]

These contrast with typical 'subsequent mention' definite descriptions, which tend to contain just two or three words (one of which is the): the Israelis, the job, the area, the parking lot. 'Inferables', definite descriptions which refer to an entity whose existence could be inferred on the basis of common knowledge plus the preceding discourse, are also typically short.

The common length difference between novel and familiar definites makes a handy gauge to compare written and spoken discourse, and indeed, we found that definite descriptions in written texts averaged $60 \%$ longer (in terms of number of words) than those in the spoken texts we looked at. More specifically we found an average of 4.5 words per definite description in the three front page news stories, as compared with an average of 2.8 words in the Car Talk segment. Even more dramatic is the difference in numbers of long definites as compared with short definites. In the front page news stories $42 \%$ of the definite descriptions (86/204) had more than 3 words, whereas only $8 \%(7 / 83)$ of the definites in the Car Talk excerpt were long by that standard.

(A parenthetical note: we also collected data from articles in the sports sections of our newspapers. It is interesting to note that these data fell between the front page news stories and the spoken data. More specifically, the average number of words per definite NP in the sports stories was 3.9, and 25\% (31/123) of the definites were longer than 3 words. Presumably this reflects the more casual, conversational, style of sports reporting.)

The lack of long, entity-introducing, definites in the spoken data support the suggestion by Du Bois 1986, Lambrecht 1994, and others that there is a tendency toward one new piece of information per utterance in spoken language. Lambrecht discusses the sentence in (14)

(14) I hope we will meet again for more than five minutes. [Lambrecht 1994, 237]

understood as uttered after a brief pleasant meeting. Lambrecht notes that utterance of (14) with a single focal stress on either minutes or again conveys the wrong understanding, and stress on both constituents is odd. The result is that the speaker would be required to break (14) up into two utterances to convey her desire that they meet again, and for more than five minutes. (Compare Lambrecht 1994, 2378 , and the works cited there.) Presumably in conversational contexts the new information which would be contained in long NPs in a written text is introduced in separate clauses using indefinites and familiar definites.

The important issue for present purposes is explaining the difference between the written and spoken data. Within the classical theory we are free to put forward an explanation based on the fact that in written language one can go at one's own pace and reread at will, thus having to rely less on short term memory. The obvious result is that people are able to process more new information per written clause than per spoken one, so that new information of secondary prominence can be smuggled in via definite descriptions without having to be 
asserted. On the familiarity view of definites the long, entity-introducing definites would have to be regarded as allowed only with Lewis's principle of accommodation (Lewis 1979). As noted above, I have argued elsewhere that this move is unsatisfactory (see Abbott 1999); here we have the additional problem that we would have to chalk up the difference between written and spoken texts to differences in how accommodating readers are as opposed to listeners, but since the same people assume both roles this does not seem to be a promising approach.

\section{Explaining problematic examples}

\section{1. 'The only' NPs}

A SALT referee has pointed out that if the classical theory is correct, we have some explaining to do about why NPs of the form the only $N^{\prime}$ are not felt to be redundant. A full story would involve an analysis of adjectival only, and that I do not have. The analysis of adverbial only (as in Only Mary left) proposed in Rooth 1985, 1992 does not seem to apply totally straightforwardly to adjectival only, although intuitively the same kind of meaning is involved in both cases, including the property of association with focus. Nevertheless some considerations suggest that such NPs do not argue against the uniqueness theory. First, in general it seems plausible to regard the article as determined by the content of the $\mathrm{N}^{\prime}$ (plus the context of utterance) rather than the other way around. That being the case we would view the as agreeing with the uniqueness expressed by only, and as such would not expect it to cause a felt redundancy any more than the plural suffix on apple in a phrase like two apples is felt to be redundant. In this respect NPs of the form the only $N^{\prime}$ are like definites with superlatives, e.g. the littlest angel.

One might respond that in the case of two apples or the littlest angel, the number word and the adjective are supplying additional elements of meaning, while in the case of the only $N^{\prime}$ only expresses only what is already expressed by the on the favored analysis. However although this might be truth-conditionally correct (and I believe it is), it seems that only adds or modifies meaning in a broader sense of 'meaning'. For one thing there is the well-known fact that only serves as a negative polarity licenser (though only of intermediate strength-see Horn 1996). (15) shows its contrast with the in this respect. ${ }^{5}$

(15) a. The only person he ever confided in at all was his priest.

b. The person he (*ever) confided in (*at all) was his priest.

Speaking vaguely and metaphorically, it appears that adjectival only expresses in a more overt way the uniqueness proposition that is part of the meaning of the and expresses it in a negative way. That is, while we might represent the truth conditions for the king of France is bald as in (16a), the logically equivalent (16b) might be a better representation of the only king of France is bald,

$$
\begin{aligned}
& \text { a. } \exists x[\text { king of France }(x) \wedge \forall y[\text { king of France }(y) \rightarrow y=x] \wedge \text { bald }(x)] \\
& \text { b. } \exists x[\text { king of France }(x) \wedge \forall y[\neg y=x \rightarrow \neg \text { king of France }(y)] \wedge \\
& \text { bald (x)] }
\end{aligned}
$$

where the boldface is intended to reflect a proposition with greater foregrounding.

There are other curious differences between the and the only. Compare (17a,b): 

a. Mary is the only person to pass.
b. Mary is the person to pass.

The most prominent interpretation of (17a) is epistemic-a statement of fact. The infinitival clause is a subject relative and the time reference is past. The only interpretation for (17b) is deontic - a statement of advice or urging. The infinitive is an object relative and the time reference is future or irrealis. Supplying an object in the relative forces the epistemic reading, and without only the sentence is ungrammatical: ${ }^{6}$
a. Mary is the only person to pass the test.
b. * Mary is the person to pass the test.

Whatever the correct analysis of NPs of the form the only $N^{\prime}$, their existence does not seem to lend support to the familiarity theory of definiteness since frequently, as in the examples above, such NPs do not refer to entities presumed to be familiar to the addressee

\subsection{Non-unique definites}

The other sort of problem case is 'non-unique' definites. These are examples of definite descriptions whose descriptive content applies to more than one entity in the universe of discourse, even if we regard the universe of discourse as contracted to meet the needs of the moment (as we must do for interpretation of quantified NPs generally and not just definite descriptions). Bertrand Russell noted that "we do, it is true, speak of "the son of So-and-so" even when So-and-so has several sons" (Russell 1905, 200). Some other examples are given in (19).

a. Toward evening we came to the bank of a river. [from Christophersen 1939: 140; cited in Du Bois 1980, 233]

b. The boy scribbled on the living-room wall. [= Du Bois 1980, ex. 86; italics added]

c. [Hotel concierge to guest, in a lobby with four elevators] You're in Room 611. Take the elevator to the sixth floor and turn left. [= Birner \& Ward 1994, ex. 2b]

d. No problem, I'll get the maid to do it. [= Epstein 1999, ex. 2a]

A number of analyses of examples like those in (19) have been put forward. As noted by Epstein 1999, some of these involve abandoning the view that the definite article implies uniqueness, but others do not require that step. Ojeda 1993 argues that so-called 'non-unique definites' refer to 'nonatomic pairwise disjoint subsets of an appropriately structured universe of discourse' (p. 248). Epstein proposes an analysis in which the definite article is licensed by a role associated with the description in question, and where the NP itself may either denote an entity via that role, or denote the role itself, depending on context and specifics of the example in question.

A complete discussion of non-unique definites would go beyond the limited scope of this paper. Here I just want to suggest a possible explanation for some instances, including those in $(19 \mathrm{c}, \mathrm{d})$ above, which relate them to the classical theory. I want to suggest that the NPs in question are to some extent fixed expressions or collocations, which arose during a time when there was only one possible referent in the typical discourse context. Some support for this idea comes from the variation in article use within English. Compare American English the hospital with British hospital, and within American English the difference between 
the hospital and school. Another pair (cited in Bolinger 1975, 103) is given in (20).
a. I heard it on $*$ (the) radio.

b. I saw it on (*the) TV

This kind of idiosyncratic variation is characteristic of expressions which are prepackaged wholes. I want to make clear that I am not claiming these are idioms; the semantics for these expressions should be compositional, while their syntax includes cooccurrence constraints.

Whatever the correct analysis of these non-unique definites, their existence does not in any obvious way lend support to the familiarity theory. In examples such as those cited above the referent of the definite would typically not be presumed to be familiar. Instead these examples would most naturally be used to introduce new entities into the discourse context. Of course the category is a familiar one, but the category is also unique. The particular entity being referred to, on the other hand, is not presumed to be known to the addressee. Indeed, if familiarity includes the idea that the addressee knows which particular entity is being referred to (as it usually does), then it must be uniquely identifiable on the basis of the description used plus possibly contextual information.

\section{Explaining the appeal of familiarity}

Our confidence in the classical theory of definite descriptions would be increased if we could presuppose it while providing a good explanation for the appeal of the familiarity theory. One quick point can be made: the vast majority of definite descriptions in ordinary conversation, at least according to our data, do denote entities that are either known to the addressee or whose existence can be inferred by them. Consider the excerpts in (21). ((21a) is from Car Talk. (21b) is from Wolfson 1976, 160-61; cited in Prince 1981, 238.)

a. In order to get the anti-lock brakes to engage you've gotta stomp on the pedal. That's how they work. If you don't do that then you don't engage the anti-lock. If you do that, however, you lose control because it doesn't work when you only have anti-locks in the back. The thing skids like crazy. I happen to know because I've done it. And it, I would rather not have it and be able to not invoke the abs at all and just drive like a human being.

b. ...she was going to a luncheon and the women were honking the horn outside.... And usually she lets the door open but she didn't this time. So she comes running down the steps and...

In (21a) the existence of the brake pedal is easily inferred. The remaining definites In (21a), (the anti-lock (brakes)/abs, the back and the thing) are all subsequent mentions. In (21b) all but the steps are inferables. The point is that, supplemented (illegitimately, in my opinion) with a Lewis style accommodation principle, all the definites in these typical samples can be seen as denoting entities familiar to the addressee, if not already explicitly introduced into the discourse context. So a lot of the time, especially if we stick to spoken language, the familiarity theory looks right. Of course I am claiming that each of the definite articles in (21) is licensed by the uniqueness in context of its intended referent and not that referent's familiarity.

I think there may be other, less happy, factors involved in the appeal of the familiarity theory. One is a certain vagueness in the concepts of 'familiarity' and 
'discourse context', which allows for quite sharply different construals and a consequent lack of clarity on the exact predictions of the theory. One of the benefits of formalization is that vaguenesses often become more noticeable, and the current case is no exception. In her well-known formalization of the familiarity theory, Heim 1982, 1983 used on the one hand a rather stringent sense of familiarity, one which corresponds to the 'discourse-old' notion in Prince 1992. Felicitous use of a definite NP (including pronouns with definite descriptions) required a denotation whose existence was already a part of the discourse context, where the discourse context was assumed to be empty at the beginning of a conversation. '[A]n NP is..."familiar" in a text if it...is coindexed with another NP that precedes it in the text' (Heim 1982, 300). On the other hand, and somewhat inconsistently, she also intended the presupposition of existence of a referent associated with definite NPs to be part of the common ground, in the sense of Stalnaker 1974, 1978. (See the discussion in Heim 1982, 285ff.) This would be a notion more like Prince's 'HEARER-old', and would be closer to the ideas of Christophersen, usually cited as the earliest supporter of the familiarity theory. 'Now the speaker must always be supposed to know which individual he is thinking of; the interesting thing is that the the-form supposes that the hearer knows it too' (Christophersen 1939, 28).

Even if, contrary to the view supported here, we were to settle on being hearer-old as the requirement for definiteness, ${ }^{7}$ there would still be some open texture in spelling out exactly what that requires or allows. This is because of play in epistemic notions inherited in the concept of being familiar to the hearer. Philosophers distinguish between occurrent and tacit beliefs. Roughly speaking one is conscious of one's occurrent beliefs, whereas tacit beliefs, such as the belief that zebras don't wear overcoats in the wild (to use a standard example), have not crossed one's mind but would be readily acknowledged on presentation. If this distinction is ignored the door is left open to a potentially vast population of discourse referents. Take the definites in (22) for example.
a. Will the last person to leave the room please turn out the lights?
b. In her talk, Baldwin introduced the notion that syntactic structure is derivable from pragmatic principles. [= Birner \& Ward 1994, ex. 1a]

(22a) certainly doesn't require that the addressee (or the speaker for that matter) know who will be the last person to leave the room. On the other hand one could argue that both speaker and addressee know tacitly that in all likelihood somebody will be such a person, and that therefore their shared model of the discourse context (taken in a broad sense as their common ground) must include such a person. Similarly in (22b), as soon as the definite is uttered the addressee must accept the existence of the notion in question. In a sense notions have necessary existence, so one could argue that they should always be part of the common ground-part of everyone's tacit acquaintance. In fact on this generous understanding of 'familiarity', it could be argued to follow from uniqueness: if the definite description supplies sufficient descriptive content for the addressee to uniquely identify a referent then the inference of existence of that referent is immediate.

I am not suggesting that anybody has ever made this type of argument, which pushes the vagueness in the notion of familiarity to the extreme. In fact the greatest prestige for the familiarity theory in recent times has come from its formalization in Discourse Representation Semantics, which has been forced to resolve some of this equivocation in a way which has allowed counterexamples to be raised against it. My point here is that prior to the explicitness introduced in the formalization of the familiarity theory, the vagueness of the essential concepts may have leant it support which it did not deserve. 


\section{Concluding remarks}

This paper offers additional support for the classical theory of definite descriptions from three different perspectives - the uniqueness component, the existence component, and patterns in spoken vs. written language. I have also tried to address the few problems I know of that it faces; and to sketch some lines of explanation for the appeal of the familiarity theory. There is undoubtedly more to be said on this subject, which seems to continue to excite at least some people today as much as it did Russell at the turn of the century. Who can say what the next hundred years will bring. ${ }^{8}$

\section{Endnotes}

${ }^{1}$ See Apostolou-Panara 1994 for description of a construction in Greek which may have been influenced by these hyperbolic constructions in English.

${ }^{2}$ On the view in Epstein 1996, examples with stressed the are grouped with others where the is not stressed, in a category which Epstein argues expresses 'prominence' as a distinct element of significance. There is not space here to explore this proposal fully, so I will just note briefly two potential problems. One, alluded to in the text, is the vagueness of the notion of 'prominence'. The other is the potential loss of generalization in the light of exaggerated uses of other expressions that have uniqueness as part of their literal meanings, e.g. unique.

${ }^{3}$ McNally 1998, p. 385, n. 33, acknowledges the possibility of this alternative. I am glossing over a number of details here, in particular the problem of the infelicity of an XP phrasal adjunct in enumerative existentials, as shown below:

$$
\text { Who can we get to draw that? \#Well, there's the VP for Smut available... }
$$

See Abbott 1993 for an account consistent with the line of attack supported here.

4 'We' = myself and my research assistant, Mingyu Sun. I am grateful to Fernanda Ferreira and Doug Davidson for making the Car Talk excerpts available to us, and to Mingyu for locating the newspaper stories and collecting and tabulating the data reported here.

5 Horn 1996, citing Hoeksema 1986, observes that accounting for the polarity licensing on the part of the only (and also superlatives (the $X$-est)) is problematic. The environment is not strictly downward entailing. As Horn following Hoeksema notes, 'if Kim is the youngest American to have \{ever/yet \} climbed Mt. Everest, it doesn't follow that Kim is the youngest American to have climbed Mt. Everest with a 500 pound gorilla strapped to her back' (Horn 1996, p. 33, n. 26). Hoeksema suggested a weakened kind of downward-entailing criterion, involving an extra premise, for the explanation of this licensing:

$\mathrm{X}$ is the only $\mathrm{Y}$

$\mathrm{X}$ is a $\mathrm{Z}$

$\underline{\text { all } \mathrm{Z} \text { are } \mathrm{Y}}$

$\therefore \mathrm{X}$ is the only $\mathrm{Z}$

However since the plain old definite article would also meet this criterion, it does not seem to have solved the problem. Note the inference in (i).

(i) Sue is the principal at the high school. Sue is a female high school principal. All female high school principals are high school principals. Therefore Sue is the female principal at the high school. 
Atlas 1966 also points out problems for Hoeksema's weakened downward entailment criterion, although his argument here appears flawed (pp. 275f).

Curiously, as pointed out to me by Jack Hoeksema, generic definite descriptions do license some polarity items, though as Horn has pointed out, they seem to require a negative or affective outcome context. The contrast in (ii) is from Hoeksema (p.c.), and the one in (iii) is from Horn (p.c.).

(ii) a. The student who talks back to him at all gets an F.

b. *The student who talked back to him at all got an $\mathrm{F}$.

(iii) a. The student who touches a drop of scotch in the dept. office is in deep shit/will go straight to hell.

b. *The student who touches a drop of scotch in the dept. office will notice the smoky peat flavor of this Highlands single malt.

${ }^{6}$ I am grateful to Larry Horn for discussion of these examples, and for suggesting the 'epistemic' and 'deontic' characterizations.

${ }^{7}$ A 'discourse-old' theory of definiteness would definitely not work. Fraurud 1990 found over $60 \%$ of definite NPs introduced new entities into the Swedish texts she examined, and Poesio \& Vieira 1997 found similar results for English.

${ }^{8} \mathrm{I}$ am very indebted to Richard Larson for pointing out some deadly flaws in an ancestor of this paper. I am grateful to Richard Epstein, Donka Farkas, Louise McNally, Almerindo Ojeda, Anna Szabolcsi, and the audiences at two MSU colloquia for their comments on prior versions. And another thanks to Doug Davidson for making me aware of Poesio \& Vieira 1997. All of the aforementioned are hereby absolved of any and all responsibility for remaining shortcomings in the finished product.

\section{References}

Abbott, Barbara. 1993. A pragmatic account of the definiteness effect in existential sentences. Journal of Pragmatics 19, 39-55.

Abbott, Barbara. 1997. Definiteness and existentials. Language 73, 103-108.

Abbott, Barbara. 1999. Presuppositions as nonassertions. Paper presented at the $73^{\text {rd }}$ Annual Meeting of the LSA, Los Angeles, CA.

Apostolou-Panara, Athena. 1994. Language change underway?: The case of the definite article in Modern Greek. in Irene Philippaki-Warburton, Katerina Nicolaidis, \& Maria Sifianou, eds., Themes in Greek linguistics. Amsterdam: John Benjamins, 397-404.

Atlas, Jay David. 1996. 'Only' noun phrases, pseudo-negative generalized quantifiers, negative polarity items, and monotonicity. Journal of Semantics 13, 265-328.

Birner, Betty. 1991. Discourse entities and the referential/attributive distinction. Paper presented at the annual meeting of the Linguistic Society of America, Chicago.

Birner, Betty \& Gregory Ward. 1994. Uniqueness, familiarity, and the definite article in English. BLS 20, 93-102.

Bolinger, Dwight. 1975. Aspects of language. Second edition. New York: Harcourt Brace Jovanovich.

Chafe, Wallace. 1976. Givenness, contrastiveness, definiteness, subjects, topics, and point of view. In Charles $\mathrm{Li}$, ed., Subject and topic. New York: Academic Press, 25-55. 
Chafe, Wallace. 1987. Cognitive constraints on information flow. In Russell S. Tomlin, ed., Coherence and grounding in discourse. Amsterdam/Philadelphia: John Benjamins, 21-52.

Chafe, Wallace. 1996. Inferring identifiability and accessibility. In Fretheim \& Gundel, eds., 37-46.

Chierchia, Gennaro \& Raymond Turner. 1988. Semantics and property theory. Linguistics and Philosophy 11, 261-302.

Christophersen, Paul. 1939. The articles: A study of their theory and use in English. Copenhagen: Munksgaard.

Clark, Herbert H. \& Catherine R. Marshall. 1981. Definite reference and mutual knowledge. In Aravind K. Joshi, Bonnie L. Webber \& Ivan A. Sag, eds., Elements of discourse understanding. Cambridge: Cambridge University Press, 10-63.

Clark, Herbert H. \& D. Wilkes-Gibbs. 1986. Referring as a collaborative process. Cognition 22, 1-39.

Du Bois, John W. 1980. Beyond definiteness: The trace of identity in discourse. In Wallace L. Chafe, ed., The Pear Stories: cognitive, cultural, and linguistic aspects of narrative production. Norwood, NJ: Ablex Publishing Corporation, 203-274.

Du Bois, John W. 1987. The discourse basis of ergativity. Language 63, 805855.

Epstein, Richard. 1996. Viewpoint and the definite article. In Adele E. Goldberg, ed., Conceptual structure, discourse and language. Stanford: CSLI Publications, 99-112.

Epstein, Richard. 1999. Roles and non-unique definites. To appear in BLS 25.

von Fintel, Kai. 1997. Bare plurals, bare conditionals, and only. Journal of Semantics 14, 1-56.

Fraurud, Kari. 1990. Definiteness and the processing of noun phrases in natural discourse. Journal of Semantics 7, 395-433.

Fretheim, Thorstein \& Jeanette K. Gundel, eds. 1996. Reference and referent accessibility. Amsterdam/Philadelphia: John Benjamins.

Gundel, Jeanette K., Nancy Hedberg \& Ron Zacharski. 1993. Cognitive status and the form of referring expressions in discourse. Language 69, 274-307.

Hawkins, John A. 1978. Definiteness and indefiniteness. Atlantic Highland, NJ: Humanities Press.

Hawkins, John A. 1991. On (in)definite articles: Implicatures and (un)grammaticality prediction. Journal of Linguistics 27, 405-442.

Heim, Irene. 1982. The semantics of definite and indefinite noun phrases. Doctoral dissertation, Amherst: University of Massachusetts.

Heim, Irene. 1983. File change semantics and the familiarity theory of definiteness. In Rainer Bauerle, Christoph Schwarze, and Amim von Stechow, eds., Meaning, use and the interpretation of language. Berlin: Walter de Gruyter, 164-189.

Heim, Irene. 1990. E-type pronouns and donkey anaphora. Linguistics and Philosophy 13, 137-178.

Hoeksema, Jack. 1986. Monotonie en superlatieven, in C. Hoppenbrouwers et al., eds., Proeven van Taalwetenschap, TABU, Groningen.

Horn, Laurence R. 1996. Exclusive company: Only and the dynamics of vertical inference. Journal of Semantics 13, 1-40.

Kadmon, Nirit. 1990. Uniqueness. Linguistics \& Philosophy 13, 273-324.

Karttunen, Lauri. 1976. Discourse referents. In James McCawley, ed., Syntax and semantics 7: Notes from the linguistic underground. New York: Academic Press, 363-386. 
Krauss, Robert M. \& Sam Glucksberg. 1964. Changes in reference phrases as a function of frequency of usage in social interaction: A preliminary study. Psychonomic Science 1, 113-114.

Krauss, Robert M. \& Sam Glucksberg. 1977. Social and nonsocial speech. Scientific American 236:2, 100-105.

Krifka, Manfred. 1993. Focus and presuppositions in dynamic interpretation. Journal of Semantics 10, 269-300.

Kripke, Saul. 1977. Speaker reference and semantic reference. In Peter A. French, Theodore E. Uehling, Jr., \& Howard K. Wettstein, eds., Midwest studies in philosophy volume 2: Studies in the philosophy of language. Minneapolis: University of Minnesota Press, 6-27.

Lambrecht, Knud. 1994. Information structure and sentence form. Cambridge: Cambridge University Press.

Lewis, David. 1979. Scorekeeping in a language game. Journal of Philosophical Logic 8, 339-59.

Löbner, Sebastian. 1985. Definites. Journal of Semantics 4, 279-326.

Lumsden, Michael. 1988. Existential sentences: Their structure and meaning. London: Croom Helm.

Millikan, Ruth Garrett. 1984. Language, thought, and other biological categories: New foundations for realism. Cambridge MA: MIT Press.

McCawley, James. 1979. Presupposition and discourse structure. In Choon-Kyu Oh \& David Dinneen, eds., Syntax and semantics, volume 11: Presupposition. New York: Academic Press, 371-388.

McNally, Louise. 1992. An interpretation for the English existential construction. Santa Cruz: UC Santa Cruz dissertation.

McNally, Louise. 1998. Existential sentences without existential quantification. Linguistics and Philosophy 21, 353-392.

Musan, Renate. 1996. There-constructions revisited. SALT 6.

Neale, Stephen. 1990. Descriptions. Cambridge MA: MIT Press.

Ojeda, Almerindo E. 1993. New evidence for a more general theory of singularity. ESCOL '93, 247-258.

Poesio, Massimo \& Renata Vieira. 1998. A corpus-based investigation of definite description use. Computational linguistics 24, 183-216.

Prince, Ellen F. 1978. A comparison of wh-clefts and it-clefts in discourse. Language 54, 883-906.

Prince, Ellen F. 1981. Toward a taxonomy of given-new information. In Peter Cole, ed., Radical pragmatics. New York: Academic Press, 223-256.

Prince, Ellen F. 1992. The ZPG letter: subjects, definiteness, and informationstatus. In William C. Mann \& Sandra A. Thompson, eds., Discourse description: Diverse linguistic analyses of a fund-raising text. Amsterdam/ Philadelphia: John Benjamins, 295-326.

Pulman, Stephen G. 1997. Higher order unification and the interpretation of focus. Linguistics and Philosophy 20,73-115.

Rooth, Mats. 1985. Association with focus. University of Massachusetts at Amherst dissertation.

Rooth, Mats. 1992. A theory of focus interpretation. Natural Language Semantics $1,75-116$.

Russell, Bertrand. 1905. On denoting. Mind 14, 479-493. Reference is to the reprint in A.P. Martinich, ed., 1996, The Philosophy of Language, third edition. New York: Oxford University Press, 199-207.

Stalnaker, Robert C. 1973. Presuppositions. Journal of Philosophical Logic 2, 447-457. 
Stalnaker, Robert C. 1974. Pragmatic presuppositions. In Milton K. Munitz \& Peter K. Unger, eds., Semantics and philosophy. New York: New York University Press, 197-214.

Stalnaker, Robert C. 1978. Assertion. In Peter Cole, ed., Syntax and semantics, volume 9: Pragmatics. New York: Academic Press, 315-322.

Strawson, P.F. 1950. On referring. Mind 59, 320-344.

Walker, Marilyn A. \& Ellen F. Prince. 1996. A bilateral approach to givenness: A hearer-status algorithm and a centering algorithm. In Fretheim \& Gundel, eds., 291-306.

Ward, Gregory \& Betty Birner. 1995. Definiteness and the English existential. Language 71, 722-742.

Wolfson, Nessa. 1976. The conversational historical present in American English narrative. University of Pennsylvania dissertation.

van der Wouden, Ton. 1994. Polarity and 'illogical negation'. In Makoto Kanazawa \& Christopher J. Piñön, Dynamics, polarity and quantification. Stanford, CA: CSLI, 17-45.

Zeevat, Henk. 1989. Realism and definiteness. In Gennaro Chierchia, Barbara H. Partee, and Raymond Turner, eds., Properties, types and meaning, Volume II: Semantic Issues. Dordrecht: Kluwer Academic Publishers, 269297.

Zucchi, Alessandro. 1995. The ingredients of definiteness and the definiteness effect. Natural Language Semantics 3, 33-78.

Department of Linguistics and Germanic, Slavic, Asian and African Languages

Michigan State University

A-614 Wells Hall

E. Lansing, MI 48824-1027

abbottb@msu.edu 